\title{
RELAÇÃo ENTRE PLANTAS NATIVAS DO CERRADO E ÁGUA
}

\section{RELATIONSHIP BETWEEN CERRADO NATIVE PLANTS AND WATER}

\author{
Leonnardo Cruvinel Furquim ${ }^{1}$, Marcos Paulo dos Santos ${ }^{2}$, Carlos Augusto Oliveira de Andrade ${ }^{2}$ \\ Lorena Alves de Oliveira², Adão Wagner Pêgo Evangelista ${ }^{2}$ \\ ${ }^{1}$ Docente no Instituto de Ensino Superior de Rio Verde (IESRIVER) e Doutorando em Agronomia da UFG - \\ leonnardolp@hotmail.com \\ 2 Doutorando em Agronomia da UFG .marcospaulo_agronomo@hotmail.com; carlosandradeuft@hotmail.com; \\ lorena_oliveira1988@yahoo.com.br; \\ ${ }^{3}$ Professor Associado da Universidade Federal de Goiás - awpego@bol.com.br
}

\begin{abstract}
Resumo: A distribuição da vegetação no bioma Cerrado relaciona-se principalmente à profundidade do solo, uma vez que esta estabelece o estoque de nutrientes e de água no solo até o final da estação seca. O trabalho aborda a evolução das plantas nativas deste bioma, trazendo as principais adaptações anatômicas, fenológicas e fisiológicas relacionadas com a disponibilidade hídrica no solo. Redução na taxa de transpiração, investimento em sistemas radiculares espessados e profundos, dormência fisiológica de sementes e acúmulo de carboidratos não-estruturais em tecidos são as principais características adaptativas destas plantas às condições do Cerrado. Algumas espécies possuem eficiente mecanismo de ajustamento osmótico, sendo capazes de redistribuir água nos tecidos mesmo em condição de déficit hídrico, o que as permite, em taxas lentas, crescerem e se desenvolverem.
\end{abstract}

Palavras-chaves: Cerrado, disponibilidade hídrica, adaptação, plantas nativas

Abstract: The distribution of vegetation in the Cerrado biome is mainly related to soil depth, since it establishes the stock of nutrients and water in the soil until the end of the dry season. The work deals with the evolution of the native plants of this biome, bringing the main anatomical, phenological and physiological adaptations related to water availability in the soil. Reduction in transpiration rate, investment in thickened and deep root systems, physiological seed dormancy and accumulation of nonstructural carbohydrates in tissues are the main adaptive characteristics of these plants to Cerrado conditions. Some species have an efficient mechanism of osmotic adjustment, being able to redistribute water in the tissues even in the condition of water deficit, which allows them, at slow rates, to grow and development.

Keywords: Cerrado, water availability, adaptation, native plants

\section{INTRODUÇÃO}

A região do Cerrado consiste em um mosaico de vegetação, como fisionomias determinadas não apenas pelo clima, mas também por solos provenientes de diferentes materias de origem (Haridasan, 2008). No bioma predominam fisionomias de savanas estacionais de encosta sobre solos profundos com pouca disponibilidade de água, como nos Cambissolos e Latossolos (Toledo et al., 2009; Carvalho et al., 2016). Tipologias vegetais de savanas estacionais em solos rasos (campos litólicos), florestas xeromórficas semidecíduas (cerradões), e ainda, florestas baixas xeromórficas decíduas em solos arenosos (os carrascos) também ocorrem no Bioma (Toledo et al., 2009). Assim, a distribuição da vegetação relaciona-se principalmente à profundidade do solo, uma vez que estabelece o estoque de nutrientes e o teor de água do solo até o final da estação seca (Carvalho et al., 2016).

Como em toda savana, a vegetação é exposta a altas irradiâncias $(1500$ a $2500 \mu$ mol.m $\left.{ }^{2} \cdot \mathrm{s}^{-1}\right)$, altas temperaturas $\left(25-40{ }^{\circ} \mathrm{C}\right.$ ao meio-dia) e, na estação seca, baixa (10-20\%) umidade relativa do ar (Palhares et al., 2010). Embora neste bioma ocorra abundância de luz, a disponibilidade de 
água e nutrientes são fatores que limitam o crescimento da vegetação, o que faz com que ocorra maior investimento na formação de raízes (Gleeson \& Tilman 1992) para exploração de camadas profundas de solo. Para tolerarem a seca com baixo potencial hídrico, as plantas desenvolveram mecanismos como o ajustamento osmótico, acúmulo de moléculas não-estruturais, transporte de solutos a longa distância com baixo custo energético, permitindo principalmente a manutenção da abertura estomática e fotossíntese sob condições de baixo potencial hídrico no solo.

Nesta revisão foram abordadas relações entre variáveis ambientais com as plantas nativas do Cerrado, no intuito de esclarecer questionamentos ligados à diversidade das respostas fotossintéticas, morfológicas e das relações hídricas nas espécies vegetais adaptadas a este bioma.

\section{Evolução e adaptação das plantas condições do Cerrado}

Como consequência da estacionalidade e das abruptas modificações de fitofisionomias a vegetação do Cerrado desenvolveu diversas adaptações morfológicas e fenológicas. $\mathrm{Na}$ morfologia dessas plantas podem ser observados sistemas subterrâneos espessados e profundos, possibilitando o alcance de regiões do solo onde há disponibilidade de água mesmo na estação seca (Souza et al., 2005; Palhares et al., 2010). Quanto à fenologia, diversas espécies do Cerrado entram em fase de dormência durante o período seco, após abscisão foliar e morte dos ramos. A dormência fisiológica evoluiu em espécies e populações do Cerrado associadas a micro- habitats áridos, onde as sementes são dispersas no final da estação chuvosa, em condições desfavoráveis para o estabelecimento (Silveira et al., 2012). Outra característica é que essas plantas mostram rápida recuperação a queimadas, de modo que as alterações no ciclo fenológico não persistem após um ano sem fogo (Silvério et al., 2015). Em algumas espécies o efeito do fogo impacta positivamente, estimulando a floração, sendo esta característica um traço adaptativo que ainda é pouco estudado (Pausas, 2017).

Em muitas espécies, especialmente nas Poaceae, modificações no metabolismo de carboidratos solúveis tem se mostrado estratégias potenciais para a sobrevivência em condições adversas. O armazenamento de carboidratos nãoestruturais como a rafinose no final da fase de crescimento vegetativo e despolimerização destes nos períodos com intensa demanda energética, protegem a planta contra vários tipos de condições ambientais adversas, como a restrição hídrica, alta salinidade e temperaturas extremas (Souza et al., 2005).

As espécies do Cerrado tendem a ter área específica foliar mais baixa e menores concentrações de nutrientes do que as espécies florestais. Em contrapartida, investem mais em casca (Hoffmann et al., 2009), raízes e carboidratos não-estruturais. Como consequência desses mecanismos estas espécies apresentam taxas de crescimento mais baixas e maior condutância hidráulica por unidade de área foliar que as espécies de outros biomas (Hoffmann \& Franco, 2008), o que lhes permite utilizar mais eficientemente a água, que no Cerrado é menos disponível. De acordo com Palhares et al. (2010) 
durante o período seco, existem espécies que deprimem a taxa de assimilação de carbono em até $50 \%$ (principalmente entre 12 e 14 horas, período de maior irradiância solar, temperatura mais alta e menor umidade relativa do ar), enquanto outras espécies mantêm inalterada a taxa de assimilação de carbono.

Estratégias particulares de anatomia da madeira dentro das espécies do Cerrado também evidenciam mecanismos de adaptação ao déficit hídrico. O grande diâmetro dos poços de vasos nas espécies de Cerrado indica um investimento em um transporte de açúcar mais eficiente para órgãos adjacentes (Dória et al., 2016). Esses poços de raios vasculares são eficazes no transporte de açúcar osmoticamente ativo (Bucci et al., 2003) dessas células do parênquima em vasos embolizados, proporcionando um mecanismo osmótico para a reversão do embolismo (Nardini et al., 2011). Reduções na concentração de amido em células do parênquima transformariam essas células em pias para o floema (Dória et al., 2016). Como resposta, o floema descarregaria açúcares e água para estas células, através dos seus raios, gerando a força motriz necessária para reabastecer o xilema e potencialmente reverter a embolia (Salleo et al., 2009; Nardini et al., 2011).

É importante apontar que as estratégias de adaptação à seca não se restringem ao xilema. As características das folhas (densidade de estômatos, condutância estomática, ceras epicuticulares), profundidade de enraizamento, processos fisiológicos (capacidade fotosintética) e traços fenológicos (deciduidade) também são variáveis que podem influenciar as respostas das plantas ao déficit hídrico (Dória et al., 2016).

\section{Anatomia, morfologia e fisiologia das plantas do Cerrado}

O Cerrado tem sua flora dividida em dois grupos de espécies, as gramíneas que tem um estrato rasteiro bastante desenvolvido e um estrato lenhoso não muito denso (cobertura arbórea de 10 a 60\%) com copas de arvores que não formam um dossel contínuo, árvores baixas (3 a 5 metros), inclinadas, tortuosas, com ramificações irregulares e retorcidas (Ribeiro \& Walter 1998; Einten, 2001; Felfili et al., 2002).

No estrato rasteiro as folhas são geralmente pequenas (microfilas) e sua textura e consistência menos rígidas se comparadas as do estrato arbóreo. A raízes são superficiais, indo até pouco mais de $30 \mathrm{~cm}$. Os órgãos vegetais têm base curta, geralmente subterrâneo desenvolvido pela superposição de folhas basais carnosas em camadas que reservam nutrientes, que protegem uma gema central de situações extremas de frio ou calor. Os tubérculos são lenhosos (xilopódios), com gemas e reserva de água e de nutrientes, próprios de plantas adaptadas a extensos períodos de seca, que possibilitam a brotação do vegetal ao final do período seco, o ramo gemífero (sóboles) que brota de um pequeno bulbo e se separa formando um novo indivíduo (Embrapa, 2017).

O estrato arbóreo apresenta súber ou cortiça (tecido vegetal de proteção) ao redor de caules e raízes de plantas que cresceram em espessura. Os caules subterrâneos têm função de reserva (xilopódio) e com gemas que permitem a rebrota das plantas após a estiagem e as queimadas. Nas plantas lenhosas, a casca protege as árvores do Cerrado contra a ação do fogo. 
Essas plantas tanslocam fotoassimilados para o sistema subterrâneo nos períodos de seca; crescem sob baixas concentrações de nutrientes e $\mathrm{pH}$ ácido; acumulam alumínio nas folhas; fazem ajustamento osmótico das raízes, possibilitando a entrada de água nos meses secos e a continuidade da transpiração e da fotossíntese (Scariot et al., 2005). A folhas são grandes (macrofilia), providas de pelos e de tomento (conjunto de pelos diminuídos e rígidos) e apresentam tricomas tectores. Os estômatos são pequenos (média de $24 \mu \mathrm{m}$ de comprimento e $15 \mu \mathrm{m}$ de largura). Os órgãos vegetais são rígidos (esclerofilia), principalmente folhas, em função do desenvolvimento do esclerênquima, que é um tecido de sustentação dos vegetais constituído por células espessas e rígidas (Embrapa, 2017).

Com essas características peculiares das folhas a planta diminui a perda de água por evaporação, além de refletir parte dos raios solares, impedindo que a folha superaqueça. Os estômatos pequenos e em grande quantidade ajudam a controlar a perda de água por transpiração, sendo sua abertura e fechamento mais rápidos. $\mathrm{E}$ os tricomas tectores auxiliam na manutenção de uma camada mais úmida ao redor da folha, o que também contribui para que as folhas não percam água em excesso para o ambiente (Sakita, 2013).

$\mathrm{Na}$ estação seca, as gramíneas, secam e morrem favorecendo a ocorrência e a propagação das queimadas, podendo ser de origem natural ou antrópica (Klink \& Solbrig, 1996; SalgadoLabouriau \& Ferraz-Vicentini, 1994). Por outro lado, as plantas adultas estão expostas a altos níveis de irradiação solar, mas possuem um sistema radicular longo e pivotante, permitindo atingir profundidade superior a 10 metros (floresta invertida), abastecendo-se de água em camadas permanentemente úmidas do solo. Essas, por permanecerem úmidas ao longo do ano, asseguram uma fonte de água estável para as plantas, minimizando os efeitos do déficit hídrico sazonal (Nardoto et al., 1998, Hoffman et al., 2004). A produção de folhas e a floração ocorrem durante a estação seca (junho a setembro). Na estação chuvosa (outubro a maio) as sementes germinam e a vegetação apresenta grande produção de biomassa, com incremento no diâmetro do caule (Sarmiento, 1984; Sarmiento et al., 1985).

Espécies do Cerrado também tendem a ter baixos valores de RAF (razão de área foliar), ou seja, a área foliar dividida pelo peso total da planta, indicando que as espécies de Cerrado investem menos na captura de luz. Esse valor menor de RAF é devido a menor área foliar por peso foliar (folhas mais espessas) e menor peso foliar por peso total da planta (Hoffmann \& Franco, 2003). Em termos de biomassa, plantas do Cerrado investem predominantemente em sistema radicular nos estágios iniciais de desenvolvimento, com uma razão raiz/parte aérea entre 1 e 9 para plantas entre 5 e 7 meses de vida (Paulilo \& Felippe, 1998; Moreira \& Klink, 2000). $\mathrm{Na}$ fase adulta a relação raiz/parte aérea é menor, atingindo valores próximos de 8 dependendo do tipo de fitofisionomia de Cerrado (Castro \& Kauffman, 1998; Abdala et al., 1998). Este alto investimento em raízes proporcionam as plantas atingir profundidades superiores a 7 metros, onde 
a disponibilidade de água é mais estável ao longo do ano (Abdala et al., 1998; Jackson et al., 1999).

Algumas espécies desta vegetação apresentam frutos tolerantes às altas temperaturas durante a passagem da frente de fogo (Cirne, 2002; Landim \& Hay, 1996; Coutinho 1977). Um estudo realizado por Cirne (2002) mostrou que os frutos de $K$. coriacea são eficientes na proteção das sementes durante as queimadas. A temperatura máxima externa dos frutos pode atingir valores entre $390{ }^{\circ} \mathrm{C}$ a $730{ }^{\circ} \mathrm{C}$, dependendo da sua posição na copa, enquanto que no interior do fruto a temperatura máxima é da ordem de $62{ }^{\circ} \mathrm{C}$ e essa temperatura interna não afeta a viabilidade das sementes.

\section{Absorção e redistribuição de água em plantas nativas do Cerrado}

A transpiração é o principal processo de geração de gradientes para o movimento da água no sistema solo-planta-atmosfera, pois, o maior gradiente possível de ser obtido é o que acontece entre a superfície da folha e a atmosfera (Angelocci, 2002). Esses gradientes governam a absorção e redistribuição de água nas plantas, influenciando na abertura e fechamento dos estômatos, condutividade hidráulica do xilema e das raízes (Aphalo \& Jarvis, 1991; Hartung et al., 2002).

Em regiões tropicais, de clima sazonal, como é o caso do Cerrado brasileiro, a exploração da água disponível ao longo do perfil do solo pelas plantas é diferenciada (Franco, 2002). Essa diferença ocorre devido à heterogeneidade estrutural da vegetação dessas regiões que englobam formações campestres, como o campo sujo e formações florestais, como o cerradão, diferindo na composição florística e fitossociológica (Goodland \& Pollard 1973; Goodland \& Ferri 1979).

O controle da abertura e fechamento dos estômatos é outra característica que influencia o movimento da água nas plantas do Cerrado. A regulação da abertura estomática está diretamente relacionada ao fluxo transpiratório da planta (Franco, 2005). Grande parte das espécies lenhosas do Cerrado restringe a abertura estomática durante a estação seca logo após as primeiras horas da manhã (Franco, 1998; Moraes \& Prado, 1998). Outras espécies apresentam restrição estomática mesmo durante a estação chuvosa, dependendo da demanda evaporativa da atmosfera (Franco, 1998; Meinzer et al., 1999; Franco \& Lüttge, 2002).

Este mecanismo de controle pode estar relacionado também com o comportamento fenológico da planta (Franco, 2005). Segundo Sarmiento et al. (1985), espécies decíduas (perdem suas folhas durante o período de seca) de savanas tropicais (Cerrado) teriam sistema radicular superficial, forte regulação da abertura estomática e só rebrotariam após o início da estação chuvosa. Por outro lado, espécies sempre-verdes (mantém suas folhas na copa durante todo o ano) teriam raízes profundas com suprimento adequado de água para a planta, permitindo a manutenção de altas taxas de transpiração durante a estação seca. No entanto, Jackson et al. (1999) em estudo no Cerrado do Brasil Central, constatou que muitas espécies decíduas possuem sistema radicular profundo, enquanto espécies sempre-verdes apresentam sistema radicular mais superficial, 
necessitando de estudos que relacionem mecanismos do uso da água e a fenologia em espécies nativas do Cerrado.

Os estômatos possuem capacidade de regular rapidamente a perda de água pelas plantas, porém, características próprias do sistema vascular de cada espécie também têm papel importante na determinação quantitativa do fluxo transpiratório (Franco, 2008). A relação entre a área foliar total da planta que pode ser denominada de superfície evaporativa presente, área do xilema disponível para o transporte e a capacidade de armazenamento de água no caule são características que influenciam diretamente essa determinação (Goldstein et al., 1998). Sendo assim, um valor reduzido da razão entre a área foliar e a área do xilema ou grande capacidade de armazenamento de água levam a diminuição das flutuações diurnas da transpiração e do potencial hídrico nas plantas lenhosas do Cerrado (Bucci et al., 2008). Além disso, características estruturais e anatômicas dos vasos do xilema impõem limites aos valores máximos de fluxo transpiratório (Franco, 2008).

Espécies decíduas e sempre-verdes respondem de maneira similar a variações no déficit de saturação de vapor do ar (Bucci et al., 2005). Em Schefflera macrocarpa (sempre-verde) e Caryocar brasiliense (decídua), a condutividade hidráulica específica dos pecíolos decresce consideravelmente nas horas de maior déficit de saturação do ar na estação chuvosa e na estação seca, um padrão similar ao encontrado para a condutância estomática (Bucci et al., 2003). Essas reduções na abertura estomática poderiam ser resultado de limitações hidráulicas ou uma resposta estomática direta a variações do déficit de pressão de vapor entre a folha e o ar (Yong et al., 1997).

Portanto, nota-se que para as diferentes espécies nativas do Cerrado, tanto em fase inicial de desenvolvimento quanto em plantas adultas, a seca sazonal característica, não exerce efeito marcado para sua sobrevivência.

\section{Potencial hídrico em tecidos de espécies nativas do Cerrado}

As plantas podem ser classificadas com relação a tolerância ao déficit hídrico no solo em isoídricas e anisoídricas. As plantas isoídricas são capazes de, diante da redução na oferta hídrica do solo, reduzir a condutância estomática a um nível capaz de, simultaneamente, evitar a completa dessecação foliar e manter a assimilação de carbono. Por outro lado, as plantas anisoídricas, mesmo reduzindo a condutância estomática, apresentam redução do potencial hídrico foliar a valores que não permitem o bom funcionamento do aparato fotossintético (Tardieu \& Simonneau 1998). Assim, de modo geral, as espécies lenhosas do Cerrado tais como Blepharocalyx salicifolius (murta), Caryocar brasiliense (pequi), Didymopanax macrocarpum (mandioqueiro), Erythroxylum suberosum (galinha-choca), Kielmeyera coriaceae (pausanto), Miconia ferruginata (pixirica), Roupala montana (carvalho-do-Cerrado), Qualea parviflora (pau-terra), Sclerolobium paniculatum (angá), Schefflera macrocarpa (mandiocão-do-Cerrado), Styrax ferrugineus (laranjinha-do-Cerrado) e Ouratea hexasperma (vassoura-de-bruxa) se caracterizam por um comportamento isoídrico em que, durante a estação seca, o potencial hídrico foliar tende a 
ser menor que durante a estação chuvosa (-0,2 a 0,3 $\mathrm{MPa}$ na estação chuvosa e - $-0,4$ a $-0,7 \mathrm{MPa}$ na estação seca). Porém, o potencial hídrico foliar tende a ser o mesmo (-1,4 a $-1,8 \mathrm{MPa})$ nas estações seca e chuvosa entre as 12 e 14 horas (máxima demanda respiratória) (Palhares et al., 2010).

Para tolerarem a seca com baixo potencial hídrico, as plantas desenvolveram o ajustamento osmótico (acúmulo intracelular de solutos osmoticamente ativos em resposta às condições estressantes de baixa disponibilidade de água), sendo considerado um dos mecanismos mais eficaz para manutenção da turgescência celular, permitindo principalmente a manutenção da abertura estomática e fotossíntese sob condições de baixo potencial hídrico no solo (Chaves Filho et al., 2001). Segundo Kramer (1995), uma redução de $10 \%$ no volume do vacúolo celular provoca diminuição no potencial osmótico em cerca de $11 \%$ do valor inicial. Contudo, a adição de solutos pode ser responsável por redução de até $50 \%$ no valor do potencial osmótico da célula. Assim, o ajustamento osmótico permite que o crescimento celular ocorra sob um potencial hídrico que geralmente seria inibidor de tal condição.

Chaves Filho \& Stacciarini-Separphin (2001) apresentaram o acúmulo de solutos da espécie Solanum bycocarpum St.-Hil (lobeira), com reflexos na redução do potencial osmótico, como uma resposta ao estresse hídrico, caracterizando um ajustamento osmótico. O acúmulo de solutos osmoticamente ativos nas células aumenta o gradiente de potencial hídrico, fazendo com que o potencial osmótico e o potencial hídrico da planta abaixem mais rapidamente que o do solo (Turner \& Jones 1980).

Respostas de capacidade fotossintética, assimilação máxima de $\mathrm{CO}_{2}$, condutância estomática e relações hídricas apresentadas por diferentes grupos fenológicos (decíduas, brevidecíduas e sempreverdes) de 15 espécies do Cerrado indicaram que cada grupo, embora diferente, converge para a manutenção do balanço hídrico, de forma a tornar as espécies competitivas no ambiente (Peixoto, 2007).

Ao avaliar a influência das condições ambientais de diferentes tipos de Cerrado no desenvolvimento de Styrax ferrugineus (Laranjinhado-Cerrado), S. camporum (Estoraque-do-campo) e S. poblii (Árvore-de-bálsamo), Habermann et al. (2011) relatou que o alto teor de água no solo na floresta ribeirinha aumentou a condutância estomática e a taxa de transpiração em $S$. camporum e S. Poblii, mas não de S. ferrugineus, indicando especializações para o melhor crescimento em habitats diferentes. A maior capacidade fotossintética por unidade foliar em S. ferrugineus em relação a $S$. Comparum foi comprovada por maiores taxas de assimilação de $\mathrm{CO}_{2}$ e eficiência do uso da água.

Mesmo com considerável crescimento radicular, ao final do primeiro ano de vida, as raízes das plantas jovens das espécies do Cerrado ainda se encontram em camadas de solo em que há redução da disponibilidade hídrica na estação seca a valores abaixo de $-2,5 \mathrm{MPa}$, e, portanto, fora da faixa fisiológica de muitas espécies vegetais (Palhares et al., 2010). As adaptações para reverter tal adversidade incluem a capacidade de entrar em dormência e/ou de manter a 
fotossíntese em taxas mais baixas sob tal redução do potencial hídrico foliar.

\section{CONSIDERAÇÕES FINAIS}

Embora a disponibilidade hídrica constitua uma das principais limitações para a exploração do bioma Cerrado, mecanismos como investimento inicial e contínuo no desenvolvimento radicular, ajustamento osmótico e alterações fenológicas contribuem para uso eficiente da água disponível e sobrevivência das espécies nestas regiões. Adaptações e evoluções anatômicas de tecidos epidérmicos e vasculares das espécies nativas deste bioma permitem que o fluxo de carbono na planta ocorra mesmo em condições ambientais desfavoráveis a fotossíntese. A exploração destas espécies, comercialmente e na pesquisa científica, não só objetiva a compreensão de eventos fitotécnicos adaptativos, bem como permite e abre possibilidades para que tais eventos possam ser buscados em programas de melhoramento genéticos de espécies de outros biomas, que veem sendo cultivadas comercialmente no Cerrado.

\section{REFERÊNCIAS BIBLIOGRÁFICAS}

ABDALA, G. C.; CALDAS, L. S.; HARIDASAN, M.; EITEN, G. Above and belowground organic matter and root:shoot ratio in a Cerrado in central Brazil. Brazilian Journal of Ecology, v. 2, p.11-23, 1998.

ANGELOCCI, L. R. Água na planta e trocas gasosas/energéticas com a atmosfera: introdução ao tratamento biofísico. Piracicaba, 2002. 272p.

APHALO, P. J.; JARVIS, P. G. Do stomata respond to relative humidity? Plant Cell \& Environment, v. 14, p. 127-132, 1991.
BUCCI, S. J.; GOLDSTEIN, G.; MEINZER, F. C.; FRANCO, A. C.; CAMPANELLO, P.; SCHOLZ, F. G. Mechanisms contributing to seasonal homeostasis of minimum leaf water potential and predawn disequilibrium between soil and plant water potential in Neotropical savanna trees. Trees, v. 19, p. 296-304, 2005.

BUCCI, S. J.; SCHOLZ, F. G.; GOLDSTEIN, G.; MEINZER, F. C.; FRANCO, A. C.; ZHANG, Y.; HAO, G. Water relations and hydraulic architecture in Cerrado trees: adjustments to seasonal changes in water availability and evaporative demand. Brazilian Journal of Plant Physiology, v. 20, p. 233-245, 2008.

BUCCI, S. J.; SCHOLZ, F. G.; GOLDSTEIN, G.; MEINZER, F. C.; STERNBERG, L. D. A. S. L. Dynamic changes in hydraulic conductivity in petioles of two savanna tree species : factors and mechanisms contributing to the refilling of embolized vessels. Plant, Cell and Environment, v. 26, p. 1633-1645, 2003.

CARVALHO, D. C. de; PESSOA, M. M. De L.; PEREIRA, M. G.; DELGADO, R. C.

Evolution of Cerrado vegetal cover on a river island based on orbital imaging data.

Engenharia Agrícola, v. 36, n. 6, p. 11861197, 2016.

CASTRO, E. A.; KAUFFMAN, J. B. Ecosystem structure in the Brazilian Cerrado: a vegetation gradient of aboveground biomass, root mass and consumption by fire. Journal of Tropical Ecology, v. 14, p.263-283, 1998.

CHAVES FILHO, J. T.; STACCIARINISERAPHIN, E. Alteração no potencial osmótico e teor de carboidratos solúveis em plantas jovens de lobeira (Solanum lycocarpum St.-Hil.) em resposta ao estresse hídrico. Rev. bras. Bot., São Paulo, v. 24, n. 2, p. 199-204, June 2001.

CIRNE, P. 2002. Efeitos do fogo na regeneração da lenhosa Kielmeyera coriacea em áreas de Cerrado sensu stricto: mecanismos de sobrevivência e época de queima. Tese de Doutorado, Universidade de Brasília, Brasília, Brasil.

COUTINHO, L. M. Aspectos ecológicos do fogo no Cerrado. II - As queimadas e a dispersão 
de sementes em algumas espécies anemocóricas do estrato herbáceosubarbustivo. Boletim de Botânica, v.5, p.57-64, 1977.

DÓRIA, L. C.; PODADERA, D. S.; BATALHA, M. A.; LIMA, R. S.; MARCATI, C. R. Do woody plants of the Caatinga show a higher degree of xeromorphism than in the Cerrado ? Flora, v. 224, n. 1, p. 244-251, 2016.

\section{EINTEN, G. Vegetação natural do Distrito}

Federal. Brasília: SEBRAE/DF, 2001. 162p.

EMBRAPA Cerrados. Bioma Cerrado - Flora. Disponível em http://www.agencia.cnptia.embrapa.br/Agen cia16/AG01/arvore/AG01_16_9112005852 32.html. Acesso em 14 de junho de 2017.

FELFILI, J. M. et al. Plantas da APA gama e cabeça de veado: espécies, ecossistemas e recuperação. Brasília: Universidade de Brasília, 2002. 52p.

FRANCO, A. C. Relações hídricas em plantas do Cerrado: as plantas lenhosas do Cerrado transpiram livremente? In: PRADO, C. H. B. A.; CASALI, C. A. Fisiologia Vegetal: práticas em relações hídricas, fotossíntese e nutrição mineral. Barueri, Editora Manole, 2008. p.1-11.

FRANCO, A. C.; BUSTAMANTE, M.; CALDAS, L. S.; GOLDSTEIN, G.; MEINZER, F. C.; KOZOVITS, A. R.; RUNDEL, P. W.; CORADIN, V. T. R. Leaf functional traits of neotropical savanna trees in relation to seasonal water deficit. Trees, v.19, p.326-335, 2005.

FRANCO, A. C.; LÜTTGE, U. Midday depression in savanna trees: coordinated adjustments in photochemical efficiency, photorespiration, $\mathrm{CO} 2$ assimilation and water use efficiency. Oecologia, v.131, p.356-365, 2002.

FRANCO, A. C. Ecophysiology of woody plants. In: OLIVEIRA, P. S.; MARQUIS, R. J. (Eds.). The Cerrados of Brazil: Ecology and natural history of a neotropical savanna. Irvington, Columbia University Press, USA, p. 178-197, 2002.

FRANCO, A. C. Seasonal patterns of gas exchange, water relations and growth of
Roupala montana, an evergreen savana species. Plant Ecology, v.136, p.69-76, 1998.

GLEESON, S. K.; TILMAN, D. Plant allocation and the multiple limitation hypothesis. American Naturalist, v.139, p.1322-1343, 1992.

GOLDSTEIN, G.; ANDRADE， J. L.; MEINZER, F. C.; HOLBROOK N. M.; CAVALIER, J.; JACKSON, P.; CELIS, A. Stem Water storage and diurnal patterns of water use in tropical forest canopy trees. Plant Cell \& Environment, v.21, p.397-406, 1998.

GOODLAND, R.; FERRI, M. G. Ecologia do Cerrado. São Paulo, Editora da Universidade de São Paulo, 1979. 193p.

GOODLAND, R.; POLLARD, R. The Brazilian Cerrado vegetation: A fertility gradient. Journal of Ecology, v.61, p.219-224, 1973.

HABERMANN, G.; ELLSWORTH, P. F. V.; CAZOTO, J. L.; SIMÃO, E.; BIERAS, A. C. Comparative gas exchange performance during the wet season of three Brazilian Styrax species under habitat conditions of Cerrado vegetation types differing in soil water availability and crown density. FloraMorphology, Distribution, Function Ecology of Plants, v. 209, n. 4, p. 351-359, 2011.

HARIDASAN, M. Nutritional adaptations of native plants of the Cerrado biome in acid soils. Brazilian Journal of Plant

Physiology, v. 20, n. 3, p. 183-195, 2008.

HARTUNG, W.; SAUTER, A.; HOSE, E. Abscisic acid in the xylem: where does it come from, where does it go to? Journal of Experimental Botany, v. 53, n. 366, p. 2732, 2002.

HOFFMANN, W. A. et al. Tree topkill, not mortality, governs the dynamics of savanna - forest boundaries under frequent fire in central Brazil. Ecology, v. 90, n. 5, p. 13261337, 2009.

HOFFMANN, W. A.; FRANCO, A. C. The importance of evolutionary history in studies of plant physiological ecology : examples from Cerrados and forests of central Brazil. Brazilian Journal of Plant Physiology, v. 20, n. 3, p. 247-256, 2008.

HOFFMANN, W. A. ORTHEN, B.; FRANCO, 
A. C. Constraints to seedling success of savanna and forest trees across the savannaforest boundary. Oecologia, v.140, p.252260, 2004.

HOFFMANN, W. A.; FRANCO, A. C. Comparative growth analysis of tropical forest and savanna woody plants using phylogenetically-independent contrasts. Journal of Ecology, v.91, p.475-484, 2003.

JACKSON, P. C.; MEINZER, F. C.; BUSTAMANTE, M.; GOLDSTEIN, G.; FRANCO A. C.; RUNDEL, P. W.; CALDAS, L.; IGLER, E.; CAUSIN, F. Partitioning of soil water among tree species in a Brazilian Cerrado ecosystem. Tree Physiology, v.19, p.717-724, 1999.

KLINK, C. A.; SOLBRIG, O. T. Efeito do fogo na biodiversidade de plantas do Cerrado. In G. Sarmiento \& M. Cabido (Eds.).

Biodiversidad y Funcionamento de Pastizales y Sabanas en América Latina. pp.231-244. CYTED y CIELAT, Venezuela. 1996.

KRAMER, P. J. Water relations of plants and soils. Academic Press, London. 1995.

LANDIM, M. F.; HAY, J. D. Impacto do fogo sobre alguns aspectos da biologia reprodutiva de Kielmeyera coriacea Mart. Revista Brasileira de Biologia, v.56, p.127-134, 1996.

MEINZER, F. C.; GOLDSTEIN, G.; FRANCO, A. C.; BUSTAMANTE, M.; IGLER, E.; JACKSON, P.; CALDAS L. S.; RUNDEL, P. W. Atmospheric and hydraulic limitations on transpiration in Brazilian Cerrado woody species. Functional Ecology, v.13, p.273282, 1999.

MORAES, J. A. P. V.; PRADO, C. H. B. A. Photosynthesis and water relations in Cerrado vegetation. In: SCARANO, F. R.; FRANCO, A. C. (Eds.). Ecophysiological Strategies of Xerophytic and Amphibious Plantas in the Neotropics. Series Oecologia Brasiliensis, Rio de Janeiro, Programa de Pósgraduação em Ecologia, Universidade Federal do Rio de Janeiro, v.4, p.45-63, 1998.

MOREIRA, A. G.; KLINK, C. A. Biomass allocation and growth of tree seedlings from two contrasting Brazilian savannas. Ecotropics, v.13, p.43-51, 2000.
NARDINI, A.; LO GULLO, M. A.; SALLEO, S. Refilling embolized xylem conduits : Is it a matter of phloem unloading? Plant Science, v. 180, n. 4, p. 604-611, 2011.

NARDOTO, G. B.; SOUZA, M. P.; FRANCO, A. C. Estabelecimento e padrões sazonais de produtividade de Kielmeyera coriacea (Spr) Mart. nos Cerrados do Planalto Central: efeitos do estresse hídrico e sombreamento. Revista Brasileira de Botânica, v.21, n.3, p.313-319, 1998.

PALHARES, D.; FRANCO, A. C.; ZAIDAN, L. B. P. Respostas fotossintéticas de plantas de Cerrado nas estações seca e chuvosa. Revista Brasileira de Biociências, v. 8, n. 2, p. 213220, 2010.

PAULILO, M. T. S.; FELIPPE, G. M. Growth of the shrub-tree flora of the Brazilian Cerrados: a review. Tropical Ecology, v.39 p.165-174, 1998.

PAUSAS, J. G. Homage to L . M . Coutinho: fire adaptations in Cerrado plants. International Journal of Wildland Fire, v. 26, n. 1, p. 249-251, 2017.

PEIXOTO, M.M. 2007. Variações sazonais no metabolismo de carbono e relações hídricas em espécies lenhosas do Cerrado de diferentes grupos funcionais. Brasília. Dissertação (mestrado). Universidade de Brasília 53 p.

RIBEIRO, J. F.; WALTER, B. M. T. Fitofisionomias do bioma Cerrado. In: SANO, S. M.; ALMEIDA, S. P. (Eds.). Cerrado ambiente e flora. Planaltina: Embrapa, 1998. p.289-556, 1998.

SAKITA, H.Y. Anatomia foliar de espécies lenhosas do Cerrado sentido restrito do Brasil Central. Trabalho de Conclusão de Curso (Graduação em Ciências Biológicas). Faculdade de Ciências e Letras, UNESP. 2013.

SALGADO-LABOURIAU, M. L.; FERRAZVICENTINI, K. R. Fire in the Cerrado 32,000 years ago. Current Research in the Pleistocene, v.11, p.85-87, 1994.

SALLEO, S.; TRIFILO, P.; ESPOSITO, S.; NARDINI, A.; LO GULLO, M. A. Starchto-sugar conversion in wood parenchyma of fi eld-growing Laurus nobilis plants : a 
component of the signal pathway for embolism repair? Functional Plant

Biology, v. 36, p. 815-825, 2009.

SARMIENTO, G. The Ecology of Neotropical Savannas. Harvard University Press, Cambridge, USA. 1984.

SARMIENTO G.; GOLDSTEIN, G.; MEINZER, F. C. Adaptive strategies of woody species in neotropical savannas. Biological Reviews, v.60, p.315-355, 1985.

SCARIOT, A.; SOUZA-SILVA, J.C.; FELFILI, J.M. (Org.). Cerrado: ecologia, biodiversidade e conservação. Brasília, Ministério do Meio Ambiente. 2005.

SILVEIRA, F. A. O.; RIBEIRO, R. C.; OLIVEIRA, D. M. T.; FERNANDES, G. W.; LEMOS-FILHO, J. P. Evolution of physiological dormancy multiple times in Melastomataceae from Neotropical montane vegetation. Seed Science Research, v. 22, n. 1, p. 37-44, 2012.

SILVÉRIO, D. V.; PEREIRA, O. R.; MEWS, H. A.; MARACAHIPES-SANTOS, L.; SANTOS, J. O. Dos; LENZA, E. Surface fire drives short-term changes in the vegetative phenology of woody species in a Brazilian savanna. Biota Neotropica, v. 15, n. 3, p. 1-9, 2015.

SOUZA, A. de; MORAES, M. G. De; RIBEIRO,
R. de C. L. F. Gramíneas do Cerrado : carboidratos não-estruturais e aspectos ecofisiológicos. Acta Botanica Brasilica, v. 19, n. 1, p. 81-90, 2005.

TARDIEU, F.; SIMONNEAU, T. Variability among species of stomatal control under fluctuating soil water status and evaporative demand: modeling isohydric and anisohydric behaviours. Journal of Experimental Botany, 49(supl.): 419-432, 1998.

TOLEDO, L. D. O.; DOS ANJOS, L. H. C.; COUTO, W. H. do; CORREIA, J. R.; PEREIRA, M. G.; CORREIA, M. E. F. Multivariate analysis of pedological and phytosociological attributes applied to characterization of Cerrado environments in north of Minas Gerais state, Brazil. Revista Árvore, v. 33, n. 5, p. 957-968, 2009.

TURNER, N. C.; JONES, M. M. Turgor maintenance by osmotic adjustment: A review and evaluation. In Adaptation on plants to water and high temperature stress (N.C. Turner \& J.P. Kramer, eds.). Wiley Interscience, New York, p.87-103, 1980.

YONG, J. W. H.; WONG, S. C.; FARQUHAR, G. D. Stomatal responses to changes in vapour pressure difference between leaf and air. Plant Cell \& Environment, v.20, p.1213-1216, 1997. 